\title{
Topical vaginal drug delivery in the guinea pig. I. Effect of estrous cycle on the vaginal membrane permeability of vidarabine
}

\author{
Manzer J. Durrani ${ }^{2}$, Akira Kusai ${ }^{1}$, Norman F.H. Ho ${ }^{1}$, Jeffrey L. Fox ${ }^{2}$ and \\ William I. Higuchi ${ }^{2}$ \\ ${ }^{\prime}$ College of Pharmacy, University of Michigan, Ann Arbor, MI 48109 and ${ }^{2}$ Department of Pharmaceutics, \\ College of Pharmacy, University of Utah, Salt Lake City, UT 84112 (U.S.A.)
}

(Received July 11 th, 1984)

(Modified version received and accepted January 2nd, 1985)

Key words: vidarabine - estrus stage - vaginal membrane permeability

\section{Summary}

In previous studies, permeability was shown to be one of the most important factors influencing the delivery of vidarabine and its 5'-0-esters in the vaginal membrane of the mouse. The present report describes the results of the extension of these studies to the guinea pig vaginal membrane. By a vaginal smear procedure, the estrous cycle (approx. 16 days in duration) was monitored by dividing it into five stages. The vaginal membrane permeability of vidarabine was measured during each stage in a two-chamber diffusion cell. This study revealed that the permeability coefficients for vidarabine were 5-100 times higher during the early diestrus stage than during the estrus stage. Additional permeation studies on membranes at the estrus stage were performed by separating the upper layer (keratin layer combined with mucous layer) from the rest of the membrane. The low permeability coefficient of vidarabine for the upper layer suggests that this layer may be the major diffusion barrier (mainly keratin layer) for vidarabine when the drug is topically applied during the estrus stage. The immature guinea pig vaginal membranes showed permeability coefficients comparable to those values obtained from the membranes of mature guinea pigs during the early diestrus stage.

Correspondence: W.I. Higuchi, Department of Pharmaceutics, College of Pharmacy, University of Utah, Salt Lake City, UT 84112, U.S.A. 


\section{Introduction}

In the mouse, the estrous cycle affects the vaginal membrane permeability of vidarabine (9- $\beta$-D-arabinofuranosyladenine, ara-A, an antiviral agent against a broad spectrum of DNA viruses including the herpes simplex virus) to such an extent that the permeability coefficient varies 10-100-fold (Hsu et al., 1983). This may be one of the most important factors influencing the antiviral efficacy of topically applied vidarabine and its prodrugs in the treatment of herpes simplex type 2 genital infections in mice. The guinea pig has also been used as an animal model for studying genital herpes infections (Kern et al., 1978). It is an especially interesting animal model because it may be used for both primary and recurrent disease (Scriba, 1975). The present study describes the effect of the estrous cycle on the guinea pig vaginal membrane permeability of ara-A.

\section{Materials and Methods}

\section{Materials}

The $\left[{ }^{3} \mathrm{H}\right] 2$-vidarabine ${ }^{1}$ was purified by HPLC, using a stainless-steel column filled with a reversed phase $\mathrm{C}-18$ type material ${ }^{2}$. The mobile phase was $25 \%$ methanol and $0.1 \%$ acetic acid $(\mathrm{pH} 4.5)$. Radiopurity of $\left[{ }^{3} \mathrm{H}\right] 2$-vidarabine was checked with thin-layer chromatography on silica gel 60 (F-354) plates ${ }^{3}$ with a chloroform-methanol $(80: 20)$ solvent system.

The vaginal smears were stained by Papanicolaou staining reagents ${ }^{4}$. The diffusion cells and the methodology for permeation experiment have been described elsewhere (Hsu et al., 1983).

\section{Guinea pig estrous cycle determination}

Mature female albino guinea pigs (Hartley strain) were monitored for estrous cycle. Vaginal smears were obtained by a device consisting of $6 \mathrm{~cm}$ of polyethylene tubing attached to the end of a 20-gauge needle which was connected to a $1-\mathrm{ml}$ syringe. About $0.2 \mathrm{ml}$ of normal saline solution was drawn into the syringe introduced $20-40 \mathrm{~mm}$ in the vagina and then retracted into the syringe. This fluid was transferred to a microscopic slide. A new method was applied in staining the guinea pig vaginal smear. The Papanicolaou stain normally applied to human vaginal smears was used in staining the guinea pig cells. This staining procedure heightened the color, contrast, and provided greater detail of the histological picture (Papanicolaou, 1954).

\footnotetext{
${ }^{1}$ Courtesy of Dr. D.C. Baker, University of Alabama, Tuscaloosa, AL.

${ }^{2} \mu$-Bondapak ${ }^{\mathrm{TM}}$, Waters Associates, Milford, MA.

${ }^{3}$ E. Merck, Darmstadt, F.R.G.

${ }^{4}$ Fisher Scientific, Fairlawn, NJ.
} 


\section{Permeability coefficient}

As has been done previously (Yu et al., 1980) permeability coefficients were calculated from the fluxes and concentration differentials across the membrane using the following equation:

$P=\frac{V}{A \Delta C} \times \frac{d c}{d t}$

where $\mathrm{V}=$ volume of the receiver solution; $\mathrm{A}=$ diffusional area of the membrane; $\Delta \mathrm{C}=$ concentration differential across the membrane; $\frac{\mathrm{dc}}{\mathrm{dt}}=$ concentration change in the receiver chamber with time.

\section{Results and Discussion}

\section{Guinea pig estrous cycle}

Two categories of cells were found in the vaginal smears: leucocytes and epithelial cells (mucous cells, nucleated squamous cells and anucleated squamous cells). There were five stages in the estrous cycle each represented by a different smear picture. The stages were estrus, metestrus, early diestrus, late diestrus and proestrus. Figs. 1 and 2 show typical profiles of vaginal smears at estrus and diestrus stages of the estrous cycle, after being stained by a modified Pap's method (Papanicolaou, 1954). The duration of the estrous cycle was computed by using 24 individual mean values,

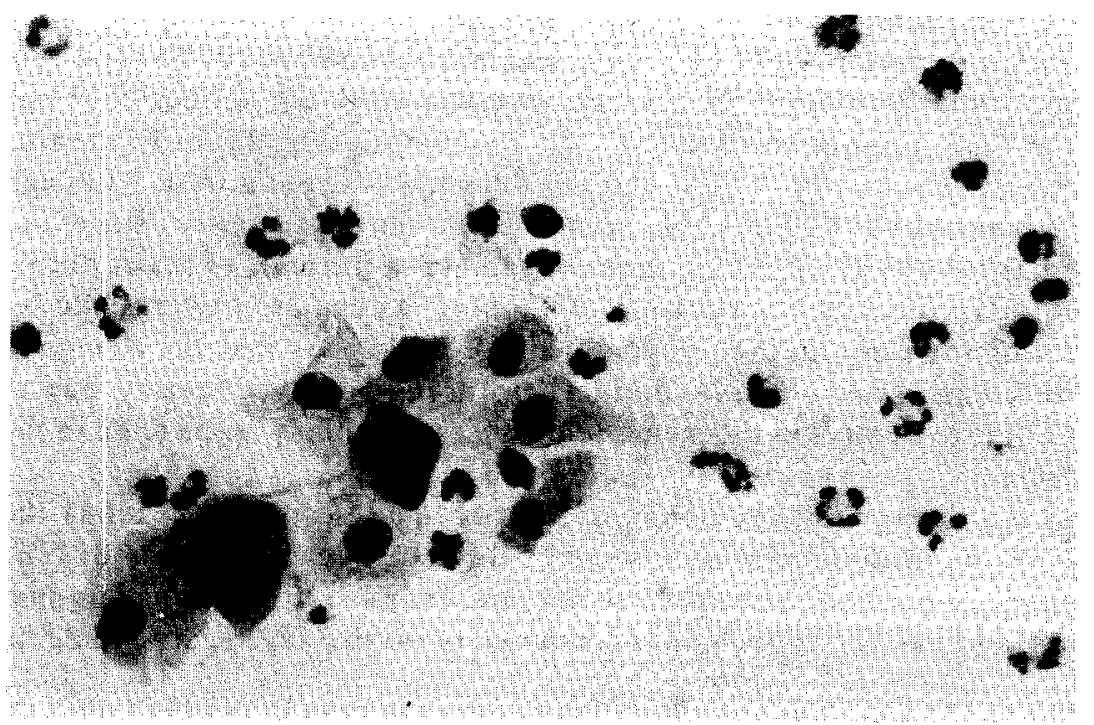

Fig. 1. Guinea pig vaginal smear, early diestrus (5-6 days). Numerous leucocytes and one squamous epithelial cell (Papanicolaou stain). 


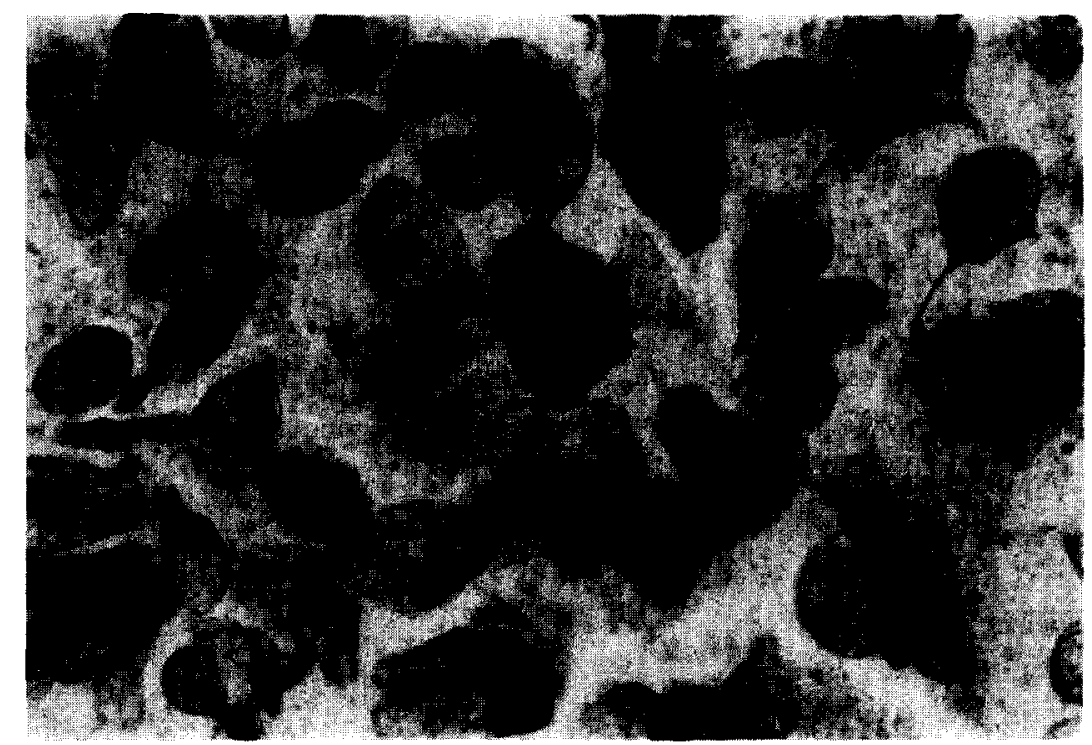

Fig. 2. Guinea pig vaginal smear, estrus (1-2 days). Abundant mucous cells (Papanicolaou stain).

one for each animal. The mean and the standard deviation were found to be $15.9 \pm 0.84$, respectively.

Guinea pig vaginal membrane permeability of vidarabine and thickness during estrous cycle stages and immature period

The vidarabine permeability coefficients and the membrane thicknesses are shown in Figs. 3 and 4, respectively. During the estrus stage the permeability was lowest and the thickness was the greatest ${ }^{5}$. In contrast, during the early diestrus stage, the permeability was the highest and the thickness was the lowest. Although the difference between the thickness of the membrane during the estrus stage and that at early diestrus was about 2 -fold, the permeability coefficients of ara-A during estrus were at least 5 times and on occasion, 100 times (50 times as an average) lower than those during the early diestrus stage. Therefore, it appears that the change in the permeability coefficient of ara-A during the estrous cycle was mostly due to significant qualitative changes in the membrane rather than simply an increase in the membrane thickness.

Because of the above findings, it was decided to microscopically examine the cross-sections of the membrane at each stage of the estrous cycle (Figs. 5-8). The photomicrographs show that the vaginal membrane consists of an epithelium and lamina propria, and that the epithelium is composed of up to 3 layers, depending on

${ }_{5}^{5}$ Since there were slight differences in the $P$-values and the thicknesses for the orifice and cervix end of the vagina, the parameters were measured separately for these two regions as shown in Figs. 3 and 4. 


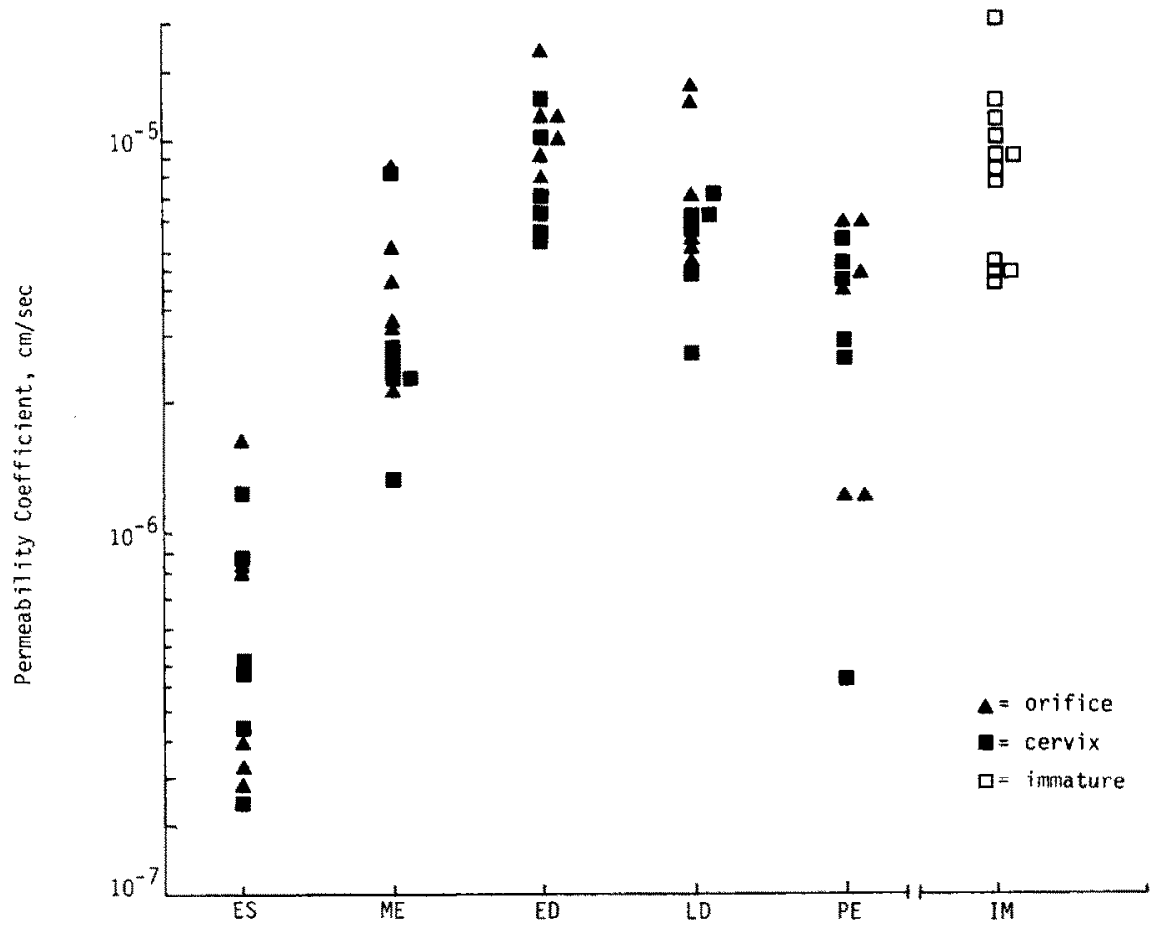

ESTROUS STAGE

Permeability Coefficient $\times 10^{6} \mathrm{~cm} / \mathrm{sec}$

\begin{tabular}{l|r|r}
\hline & Cervix End & Orifice End \\
\hline & Mean \pm S.D. & Mean \pm S.D. \\
Estrus (ES) & $0.51 \pm 0.33$ & $0.63 \pm 0.51$ \\
Metestrus (ME) & $3.25 \pm 2.28$ & $4.40 \pm 2.10$ \\
Early Diestrus (ED) & $8.01 \pm 2.93$ & $11.80 \pm 2.93$ \\
Late Diestrus (LD) & $5.74 \pm 1.65$ & $8.42 \pm 3.81$ \\
Proestrus (PE) & $3.45 \pm 1.73$ & $3.91 \pm 1.88$ \\
Imature* & $8.75 \pm 4.25$ & - \\
\hline * Total vaginal membrane permeability
\end{tabular}

Fig. 3. Guinea pig vaginal membrane permeability coefficient of ara-A during different estrous stages and immature period.

the phase of the cycle: the mucous layer (superficial), the keratin layer, and next to the lamina propria, the less mature squamous epithelium. Beneath the fibrous stroma of the lamina propria is the muscular layer. The mucous layer was observed during the late diestrus, the proestrus and the estrus stages. These results seem to show that the keratin layer may be the major barrier for drug transport.

Vaginal membranes obtained during the estrus stage were separated into two 


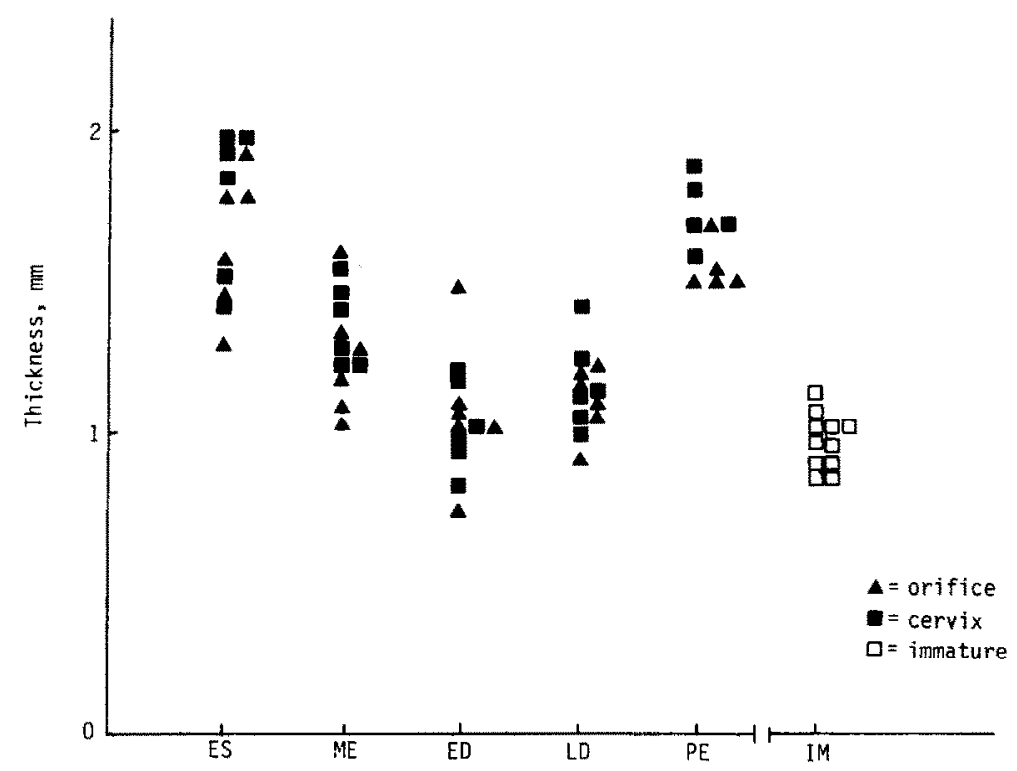

\begin{tabular}{l|c|c}
\hline \multicolumn{2}{c}{ ESTROUS STAGE } & \multicolumn{2}{c}{ THICKNESS, mim } \\
\hline & Cervix End & Orifice End \\
\hline & Mean \pm S.0. & Mean $\pm S .0$. \\
Estrus (ES) & $1.86 \pm 0.14$ & $1.73 \pm 0.15$ \\
Metestrus (ME) & $1.38 \pm 0.12$ & $1.27 \pm 0.19$ \\
Eariy Diestrus (ED) & $1.03 \pm 0.14$ & $1.08 \pm 0.22$ \\
Late Diestrus (LD) & $1.17 \pm 0.14$ & $1.11 \pm 0.11$ \\
Proestrus (PE) & $1.70 \pm 0.13$ & $1.52 \pm 0.11$ \\
*Immature & $0.98 \pm 0.09$ & - \\
\hline
\end{tabular}

* Vaginal membrane is too small to get thickness from the orifice end.

Fig. 4. Guinea pig vaginal membrane thickness during different estrous stages and immature periods.

parts using a pair of forceps and permeability experiments were conducted with each of the two components. The upper part consisted of the keratin layer combined with the mucous layer and the lower part was the combined squamous epithelium and the stroma. Vidarabine permeability coefficients determined for these two components are presented in Table 1 . The permeability coefficients for the total membrane, $P_{T}$, calculated from the data according to Eqn. 2 are also given in Table 1.

$$
\frac{1}{\mathrm{P}_{\mathrm{T}}}=\frac{1}{\mathrm{P}_{\text {upper layer }}}+\frac{1}{\mathrm{P}_{\text {lower layer }}}
$$




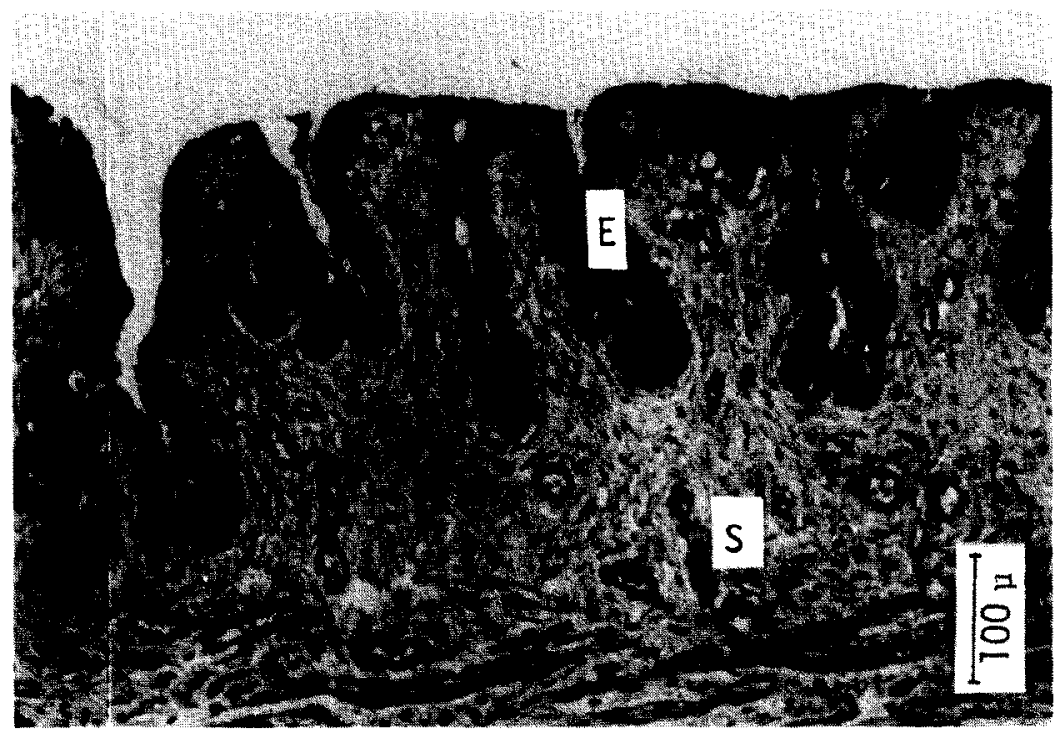

Fig. 5. Guinea pig vagina, early diestrus. Immature stratified squamous epithelium (E) overlies fibrous stroma of the lamina propria (S) (hematoxylin and eosin stain).

As can be seen, these $P_{T}$ values agree well with permeability coefficients which were directly determined using membranes obtained during the estrus stage (Fig. 3).

These results show that the upper portion, mainly the keratin layer could be a primary diffusion barrier. Furthermore the permeability coefficients for the lower

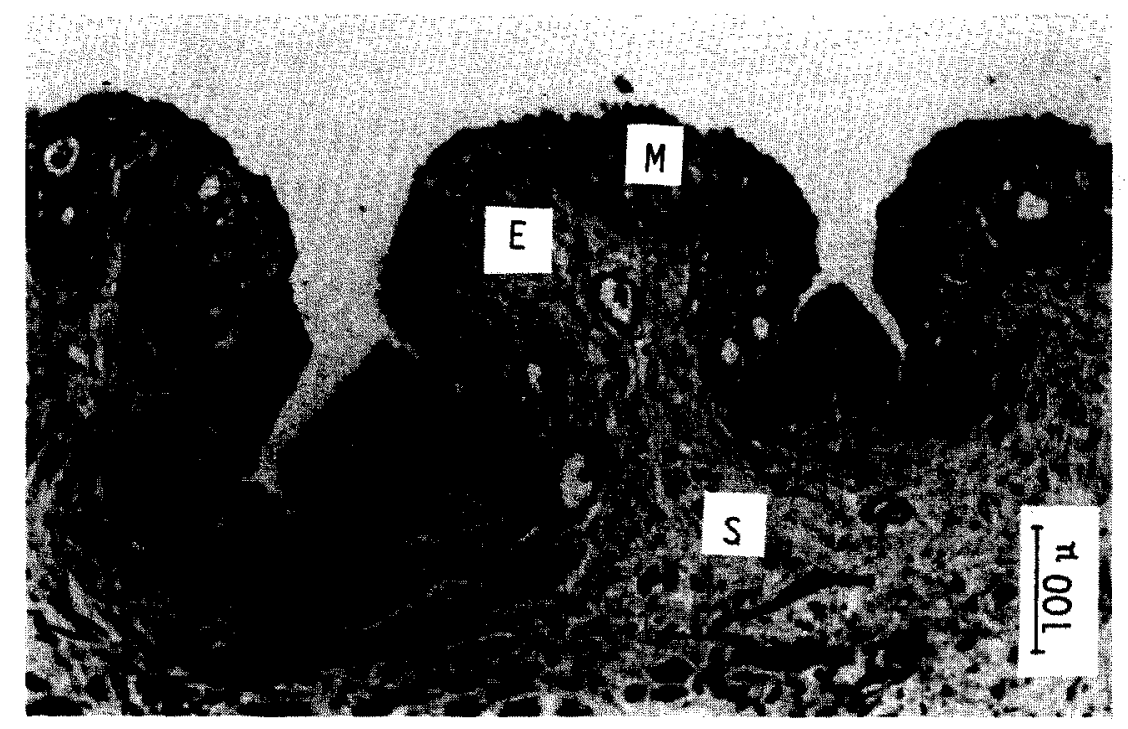

Fig. 6. Guinea pig vagina, late diestrus. Many mucous cells (M) have developed in the stratified squamous epithelium (E) (hematoxylin and eosin stain). 


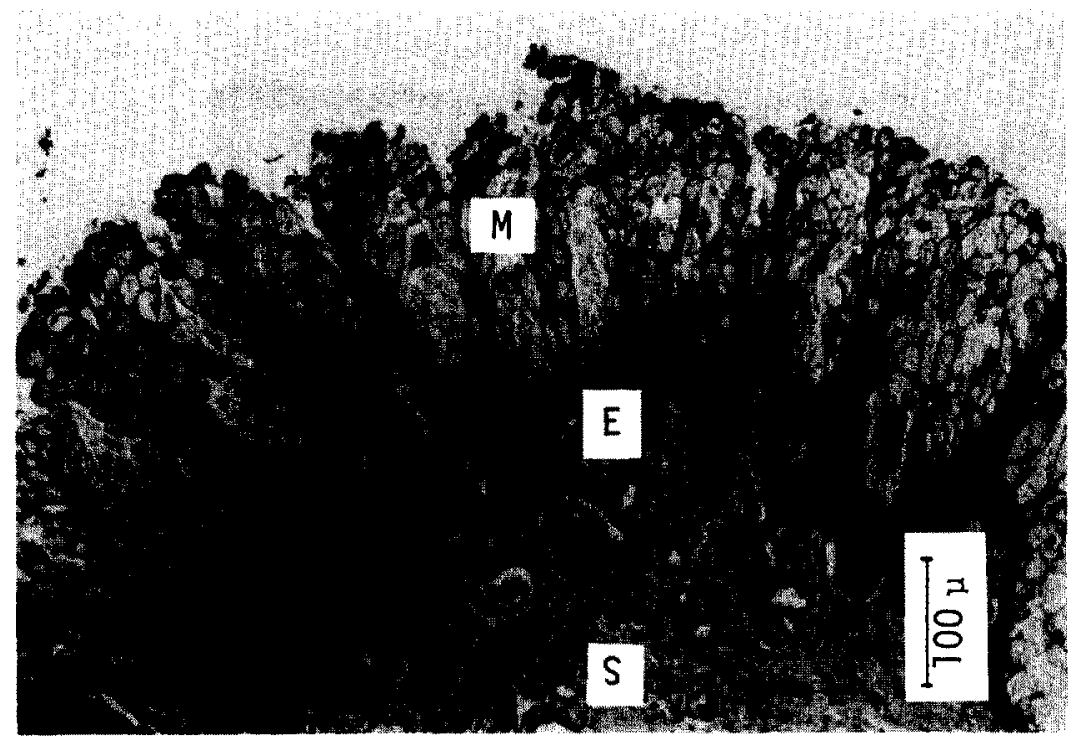

Fig. 7. Guinea pig vagina, proestrus. The epithelium is composed of a thick layer of mucous cells (M) beneath which is a thinner layer of immature stratified squamous epithelium (E) (hematoxylin and eosin stain).

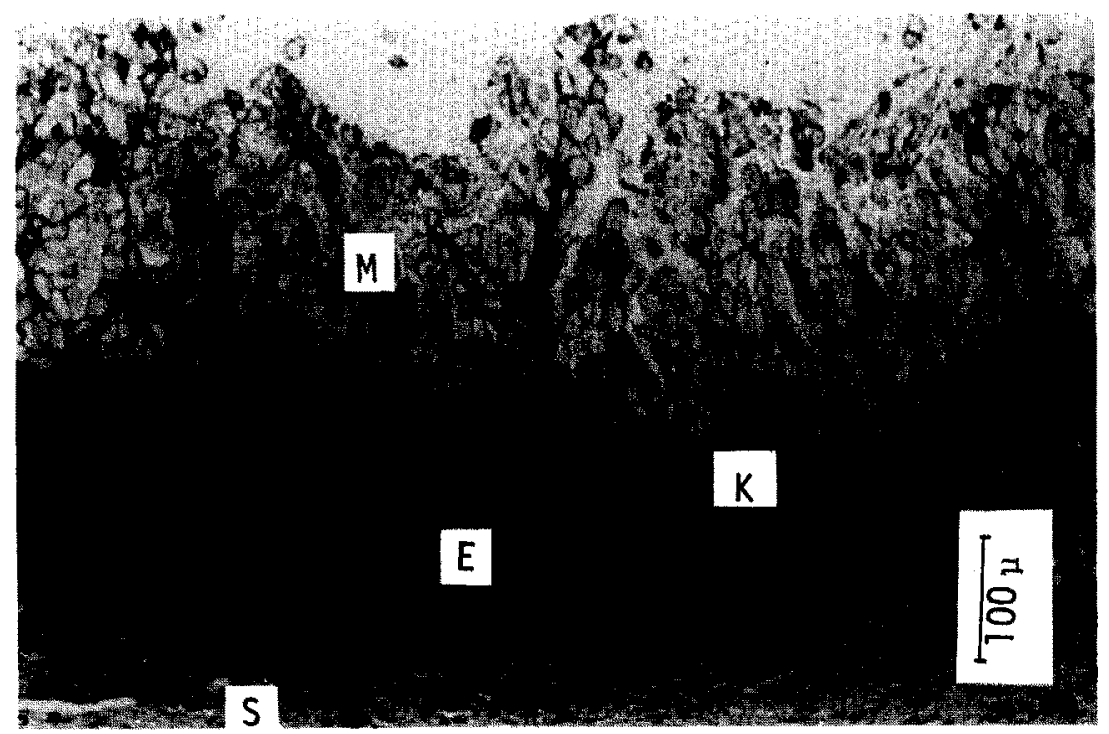

Fig. 8. Guinea pig vagina, estrus. The epithelium is composed of a thick layer of mucous cells (M) beneath which is a thick layer of immature (keratinizing) stratified squamous epithelium (K) (hematoxylin and eosin stain). 
TABLE 1

PERMEABILITY COEFFICIENTS OF THE UPPER PART AND THE LOWER PART OF THE ESTRUS MEMBRANE **

\begin{tabular}{llll}
\hline Guinea pig no. & \multicolumn{3}{l}{ Permeability coefficient $\times 10^{6}(\mathrm{~cm} / \mathrm{s})$} \\
\cline { 2 - 4 } & Upper part & Lower part & P* \\
\hline 58 & - & 1.88 & - \\
66 & 0.499 & - & - \\
62 & 0.609 & 1.48 & 0.431 \\
63 & 0.484 & 2.42 & 0.403 \\
\hline
\end{tabular}

* Calculated from Eqn. 2.

** The permeability coefficient of the upper part is significantly $(P<0.01$, by the $t$-test $)$ smaller than the lower part.

part were significantly less than those obtained for the membrane during the early diestrus stage. They were, in fact, comparable to the permeability coefficients of the membrane during proestrus and metestrus stages. Interestingly, similar conclusions were deduced in studies with the mouse vaginal membranes (Hsu et al., 1983). These findings confirm the fact that in addition to the keratin layer, there is a cycle-related low permeability layer, most likely the squamous epithelium, since its thickness does change during the estrous cycle.

Figs. 3 and 4 also present data for vaginal membranes of immature guinea pigs. These values and the thicknesses for immature membranes are comparable to those for mature guinea pigs at early diestrus. The cross-sections of immature guinea pig

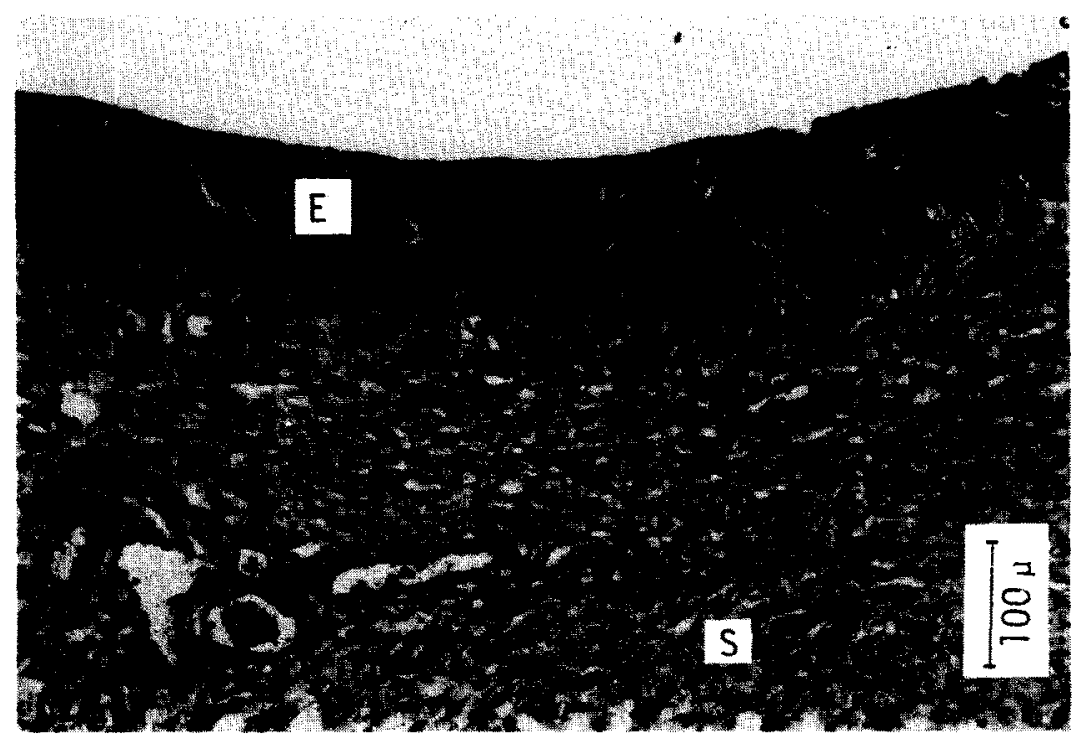

Fig. 9. Guinea pig vagina, metestrus. Mature stratified squamous epithelium overlies fibrous stroma of the lamina propria (hematoxylin and eosin stain). 


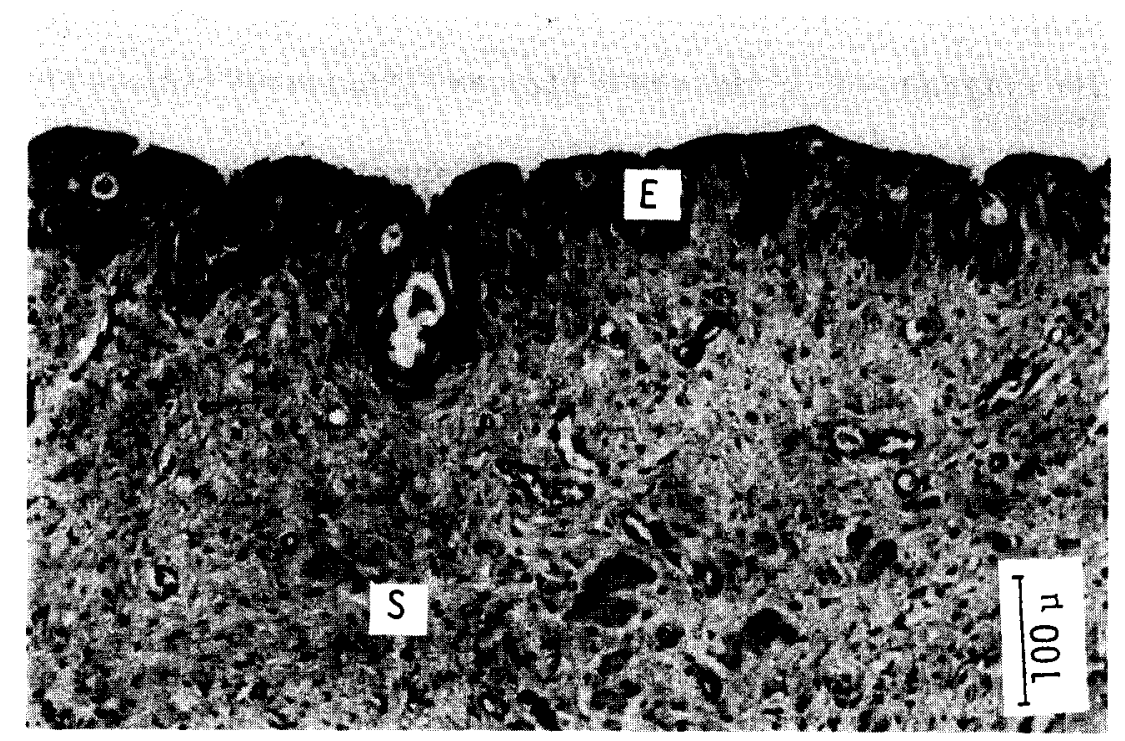

Fig. 10. Guinea pig vagina, immature. Stratified squamous epithelium (hematoxylin and eosin).

vaginal membranes (Fig. 10) also show similarities in appearance to those of the mature guinea pigs at early diestrus.

The results of the present study have shown that the influence of the estrous cycle on drug delivery can be very important. In in vivo studies using vaginally infected guinea pigs, it may be essential to consider whether immature or mature guinea pigs may be used and how the estrous cycle may be monitored; otherwise, meaningful results may not be obtained.

\section{Acknowledgements}

We are grateful to Dr. Bernard Naylor and Ms. Patricia M. Novak, Department of Pathology, Medical School, The University of Michigan, for their kind assistance in preparing the cross-sections, the permanent smears and the photomicrographs. This research was supported by NIH Grant AI14987 and AI20161.

\section{References}

Hsu, C.C., Park, J.Y., Ho, N.F.H., Higuchi, W.I. and Fox, J.L., Topical vaginal drug delivery I: Effect of estrous cycle on the vaginal membrane permeability and diffusivity of vidarabine in mice. J. Pharm. Sci., 72 (1983) 674-680.

Kern, E.R., Glasgow, L.A., Overall, J.C., Jr., Reno, J.M. and Boeżi, J.A., Treatment of experimental herpesvirus infections with phosphonoformate and some comparisons with phosphonoacetate. Antimicrob. Agents Chemother., 14 (1978) 817-823.

Papanicolaou, G.N., Atlas of Exfoliative Cytology, Harvard University Press, Cambridge, 1954.

Scriba, M., Herpes simplex virus infection in guinea pigs: an animal model for studying latent and recurrent herpes simplex virus infection. Infect. Immun., 12 (1975) 162-165.

Yu, C.D., Higuchi, W.I., Ho, N.F.H., Fox, J.L. and Flynn, G.L., Physical model cvaluation of topical prodrug delivery - simultaneous transport and bioconversion of vidarabine-5'-valerate III: Permeability differences of vidarabine and n-pentanol in components of hairless mouse skin. J. Pharm. Sci., 69 (1980) 770-772. 